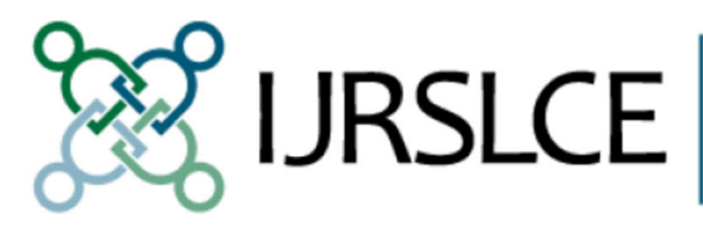

International Journal

for Research on

Service-Learning \&

Community Engagement

\title{
International Service-Learning and Community Engagement
}

\section{Brian O Donnchadha}

\section{Carol Ma}

This article was originally published at:

https://journals.sfu.ca/iarslce/index.php/journal/article/view/164/88

Recommended Citation

Donnchadha, B. O., \& Ma, C. (2015). International Service-Learning and Community Engagement. International Journal of Research on Service-Learning and Community Engagement, 3(1), Article 13. 


\title{
International Service-Learning and Community Engagement
}

\author{
Brian Ó Donnchadha \\ National University of Ireland \\ Carol Ma \\ Lingnan University
}

Section Co-Editors

One of the challenges that the scholarship of engagement has faced over the last 30 years is that of terminology. There are numerous terms to describe campus community engagement, not aided by the various forms or degrees of engagement. The terminology and semantic issues are complicated further when different languages and cultures are added to the mix. Even within this section, there are subtle differences between international service-learning, or ISL (involving travel abroad), and global service-learning (referring to the field in different countries). Here, IJRSLCE seeks to provide a space in which scholars from around the world can share their work, raise questions, examine practice, and contribute to research in this domain. By sharing knowledge and identifying similarities and common experiences, "the other" ceases to be "foreign" and is recognised as familiar.

While the journal strives for more contributions, there are two articles in this issue that center on diverse issues experienced by students using international service-learning. Coincidentally, both are in the field of health care.

The first, "Value Added: Service-Learning Outcomes for Physical Therapy Students and Community Partners in Belize" by Beitman, Gahimer, and Staples, examines the perceptions of students and community partners involved in the delivery of physical therapy in Belize. Though Belize is only English-speaking country in Latin America, the cultural differences the visiting American students experienced there provided grounds for deep learning. The absence of basic tools needed for therapeutic intervention pushed students' creativity and resourcefulness to, for instance, use bent spoons and beer bottles to assist their disabled patients. While the onsite provision of occupational and physical therapy was clearly a service, surveys of Belizean agency staff identified the need for training among local caregivers. With plans to expand the project to include service clients and community partners, steps are being made toward sustainability of services after the ISL students have left.

The second article in the "International" section of this issue, "Service-Learning in Global Health Education: The Effect of Team Dynamics on Civic Attitudes and Skills" by Chavez-Yenter, Badham, Hearld, and Budwhani, examines students' perceptions of changes in their civic attitudes and skills. It features a sample of 43 students who studied global health from a wide variety of disciplines. Results showed that students reported an improvement in their civic awareness and associated skills as a result of their participation in a service-learning course. Interestingly, while the majority of respondents were female, there was no difference between males and females regarding questionnaire results across six outcome areas. Instead, team dynamics comprised the most important contributor to change in students' attitudes.

With the growing use of international service-learning and the ever-shrinking global village, there is an opportunity for civic engagement sans frontier to have a significant influence in global knowledge transfer, increased cultural understanding, and (dare it be said) steps towards social justice. This must be carefully documented, rigorously analysed, and faithfully reported to insure that those steps can be followed by greater leaps in understanding. 